\title{
Buchbesprechungen
}

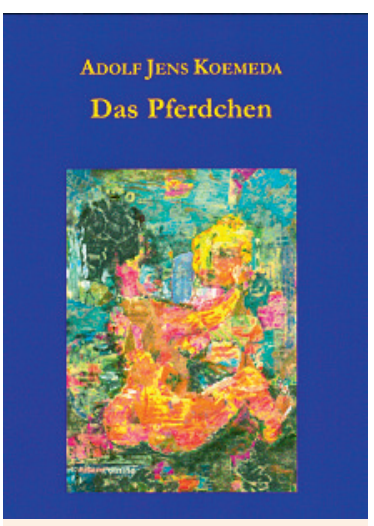

Adolf Jens Koemeda Das Pferdchen Münster: Principal Verlag; 2010.

227 Seiten. $30.50 \mathrm{CHF}$. ISBN 978-3-89969-097-2

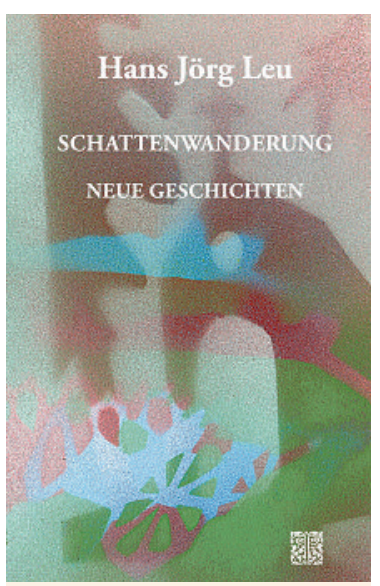

Hans Jörg Leu Schattenwanderung Neue Geschichten Egg: Thesis Verlag; 2010. 129 Seiten. 25.00 CHF. ISBN 978-3-908544-73-9

\section{Das Pferdchen}

Adolf Jens Koemeda, geboren in Prag, Arzt und Psychotherapeut, ist in der ganzen Bodenseeregion durch die regelmässig in seinem Haus stattfindenden literarischen Lesungen zum Begriff geworden. Zum vorliegenden neuen Werk schreibt Prof. Dr. med. Daniel Hell in einem Vorwort, dass dem Autor das seltene Meisterstück gelungen sei, aus der Innenperspektive die langsamen psychotischen Veränderungen einer Frau zu beschreiben. Dem ist wenig beizufügen, es sei denn, dass man mit der Beurteilung einverstanden ist und dankbar auch, dass hier eine Geschichte spannend und unterhaltend erzählt wird.

Im Buch «Das Pferdchen», mit einer Umschlagillustration des Autors, schreibt eine Frau aus dem Gefängnis an ihre Verteidigerin. Am Anfang steht die Tat, die Erschiessung des Ehemannes, dem in einem langen inneren Monolog der Lebenslauf der Mörderin folgt. Das ist raffiniert erzählt und kunstvoll mit dem fachlichen Wissen des Autors verwoben. Das Drama ist örtlich und zeitlich festgelegt, sechs Wochen nach dem ersten Bericht wird die sich anbahnende Psychose manifest. Der rätselhafte Buchtitel steht für ein Ereignis, das die Katastrophe auslöst. Der letzte Brief, formal ruhig und geordnet, datiert zehn Wochen später, vielleicht nach Abklingen des Krankheitsschubes oder als Folge einer medikamentösen Therapie. Die Briefe an die Anwältin führen unmittelbar nach der Tat von der Ordnung ins Chaos, vom sicheren biografischen Erzählen zum typisch Sprunghaften, Assoziativen und Halluzinatorischen des psychotischen Zusammenbruchs. Vielleicht ist dieser Ablauf ein Kunstgriff, mit dem der Autor die Pole absichtlich verkehrt hat. Doch Leserinnen und Leser können auch anders interpretieren. Dann hat die Tat vorübergehend eine innere Ordnung wieder hergestellt, die bei der schriftlichen Aufarbeitung erneut zerfällt. Unberührt lässt die Geschichte niemanden, das ist wohl das Beste, das von einem Buch gesagt werden kann.

\section{Schattenwanderungen}

Hans Jörg Leu, geboren 1926, Medizinprofessor an der Universität Zürich bis 1991 und langjähriger Chefredaktor der Zeitschrift für Gefässkrankheiten VASA, ist ein Mann mit vielen Talenten. Ein Künstler beeindruckender Spray-Unikate, Linol- und Holzschnitte und ein Meister im Genre der Kurzgeschichten. Die neuen Erzählungen im schmalen Band «Schattenwanderungen» könnte man als eine konzentrierte Altersprosa bezeichnen. Glasklare, präzis geschliffene Porträts und Kleingeschichten, vorwiegend von der Südseite, mit grosser Wirkung. Novaggio ist neben Baden seine zweite Heimat. Dass dort einige Dorfbewohner sich trotz Anonymisierung und Verfälschung in einigen Texten erkannt haben, hätten sie ihm etwas krumm genommen, aber die Tessiner seien tolerante Menschen, so der Autor. Es überwiegen die Herbsttöne, das matschige Braun durchnässter Kastanienblätter, das trübe Rot übrig gebliebener Zinnien und das fahle Gelb welkender Chrysanthemen. Der Novemberregen hat eingesetzt, und im Norden ist es neblig trüb und eisig kalt. Zeit der Rückschau auf verpasste Gelegenheiten, ungelebte Liebschaften und schicksalshafte Begegnungen, die auch eine ganz andere Wendung hätten nehmen können. Bei Hans Jörg Leu schärft die Distanz den Blick zurück. Melancholie ist spürbar, aber keine Resignation. Witz und Ironie kommen nicht zu kurz, sie leuchten auf in Gauner- und Militärgeschichten, oder wenn der Schulleiter mit der Putzfrau durchbrennt. Die Erinnerung ist das Leitmotiv. «Es zieht einem an die Orte zurück, an denen man seine Ursprünge zu haben glaubt, weil man sich selbst überzeugen muss, dass man dort nicht mehr leben könnte und wollte» oder spöttisch über das Gedächtnis eines Kollegen nach einer Fortbildung: «...die Erinnerung, einmal im Leben ein Bordell besucht zu haben. Und das ist etwas, was ihn in seinem späteren eintönigen Dasein in einem deutschen Institut für Pathologie aufrichten und stärken wird.»

Erhard Taverna, Urnäsch 